\title{
Concepto - Contexto
}

FELIPE CORVALÁN TAPIA

Editor Revista de Arquitectura Facultad de Arquitectura y Urbanismo Universidad de Chile a convocatoria de artículos correspondiente a la edición N 32 de REVISTA DE ARQUITECTURA, realizó

Lun llamado a repensar los alcances del vínculo entre concepto y contexto. Dos términos propuestos como relevantes para entender los límites de acción de la arquitectura, pero cuya valoración no ha estado exenta de modificaciones a lo largo de la historia de la disciplina. En esta dirección, la referencia efectuada en la convocatoria a la publicación Event-Cities 3: Concept vs. Context vs. Content (2005) de Bernard Tschumi, alentaba a los articulistas a pensar esta relación como un espacio en conflicto. Una tensión que contiene buena parte de los problemas de definición que afectan a la arquitectura, a medio camino entre la abstracción y la atención a las demandas concretas de la realidad.

Por otro lado, la posibilidad de reflexionar en torno a la idea de contexto en un sentido amplio -considerando sus implicancias no solo físicas, sino que también culturales o geopolíticas- nos permite complementar las discusiones que se han desarrollado en las últimas dos ediciones de RevisTA De ARQUITECTURA. Así, la aproximación a la "Teoría del Proyecto" realizada en el № 30 y a las "Arquitecturas Colectivas" en el №31, encuentran aquí una continuidad y al mismo tiempo un contrapunto, articulando una conversación entre tres instancias fundamentales para entender al ejercicio arquitectónico contemporáneo: teoría, asociatividad y contexto.

Abriendo el cuerpo de artículos, el trabajo de Mónica Aubán dialoga con el ya citado texto de Tschumi, incorporando un nuevo término a considerar: el afecto. Se trata de un concepto desarrollado en el ámbito de las humanidades, propuesto por la autora como clave para ampliar las estrategias de intervención utilizadas habitualmente por la arquitectura.

En el caso de Alejandro González, su investigación plantea una reflexión sobre los procedimientos de trabajo utilizados por la arquitectura contemporánea. Frente a la tradicional dicotomía entre "invención" y "repetición", el artículo reconoce en el juego la capacidad de dinamizar el vínculo entre el ejercicio arquitectónico y su contexto de acción.

Por su parte, el artículo de Butragueño, Raposo y Salgado se aproxima a la figura -a estas alturas emblemática- del arquitecto holandés Rem Koolhaas. A partir de las exposiciones "Content" y "Fundamentals", el trabajo aborda la comprensión del contexto desarrollada por Koolhaas, quizás uno de los arquitectos contemporáneos más interesados en esta cuestión.

Articulando una vinculación más directa entre obra y emplazamiento, Enrique Delgado revisita el Hospital de Venecia proyectado por Le Corbusier entre los años 1962 y 1965. El proyecto en cuestión le permite al autor establecer una relación entre edificio, contexto urbano y contexto natural, realzando el protagonismo del agua como elemento ordenador.

Orientando la discusión hacia el plano local, Paulina Alvarado analiza la configuración del barrio El Llano Subercaseaux, distinguiendo sus atributos y posibilidades de conservación frente a las dinámicas de cambio que afectan a la ciudad. En este caso, las condiciones contextuales se vinculan con la tipología arquitectónica utilizada y el modelo de ordenamiento instaurado.

A su vez, el artículo de Irene Escobar se interesa por las intervenciones desarrolladas por los pueblos originarios del Altiplano atacameño. Intervenciones que podemos caracterizar como sustentables, dando cuenta de un alto conocimiento del contexto y paisaje sobre el cual se opera. 
Por último, cerrando la secuencia de artículos presentes en esta edición, Alberto Humanes plantea el creciente desuso de las estructuras laminares, preguntándose si estamos frente al abandono definitivo de una tipología estructural tradicionalmente utilizada. Técnica, concepción espacial y contexto interactúan en este trabajo.

En cuanto a nuestra habitual sección "Reflexión Estudiantil", presentamos en esta oportunidad tres trabajos desarrollados por estudiantes de la Carrera de Arquitectura de la Universidad de Chile. En el primero de ellos, se exponen los resultados de la investigación "La otra mitad de la Quinta Monroy" realizada por Yessenia Millones. A más de diez años de su proyección, el texto analiza el impacto y estado actual del conjunto de viviendas "Quinta Monroy", realizado por el arquitecto Alejandro Aravena y el equipo Elemental. El segundo trabajo corresponde al proyecto de título "Parque de Sal en Cáhuil" de Camilo Villagrán. Un proyecto que apuesta por el desarrollo local, poniendo en valor el paisaje a través de la recuperación de unas antiguas salinas. Por último, exponemos el también proyecto de título "Museo de la Construcción Naval" de Emanuel Astete, recientemente ganador del concurso Archiprix 2017. En este caso, la intervención reconoce la presencia del río como principal espacio público de la ciudad de Valdivia, a través de un edificio-barco que ponen en valor la actividad productiva de la zona y la importancia cultural que esta posee.

Finalmente, cierra la edición № 32 de ReVISTA De ARQUITECTURA la reseña del libro Mal de proyecto. Precauciones para archivar el futuro de José Solís, escrita por el académico Max Aguirre. Una publicación que se inscribe en el ámbito de la teoría de la arquitectura, que se aproxima críticamente a la condición contemporánea de la disciplina y sus debates.

Esperamos que los contenidos que conforman este número -su interacción con ediciones anterioressigan contribuyendo a la generación de un espacio de reflexión en torno a la arquitectura. La aproximación a la noción de contexto aquí planteada busca diversificar las miradas, reconsiderando las estrategias de acción y las escalas de valoración comúnmente aceptadas por el campo arquitectónico. 